\title{
Valuation of life in long run health care programmes
}

\author{
R R WEST
}

\section{Introduction}

Almost every decision that we make necessitates cost benefit analysis, although for the majority the analysis is short circuited because the decision is trivial, preprogrammed, or given up because sufficient data are not available. Corporate decisions and long term planning decisions also necessitate implicit cost benefit analysisimplicit because corporate managers in the past have not formally collected and compared cost and benefit data for many planning decisions. Until relatively recently planning in the National Health Service was no exception. During the past 15 years, however, economists have directed particular attention to evaluating health care and a vigorous subspecialty of health economics has emerged. Health economics as a subject has enjoyed further attention in the past five years, mainly because of the reduction of the rate of growth of the NHS (and of other welfare state activities) and the consequent competition for resources.

An essential prerequisite for cost benefit analysis is knowledge of the effectiveness or the relative effectiveness of the health care programme under evaluation. ' That must remain the prime concern of clinicians and epidemiologists. ${ }^{2}$ Having established that an action does save life or does reduce disability compared with some alternative action or with inaction, cost benefit analysis attempts to enumerate the costs of the programme compared with the alternative or with no programme and the relative benefits accruing to the programme compared with the alternative or with no programme. The economist's task may be less soluble than the epidemiologist's, since he is confronted with comparing unlike commodities. For example, in evaluating coronary artery bypass graft surgery cardiologists and epidemiologists have data from randomised controlled trials comparing surgical with medical treatment about which to argue. ${ }^{3}$ In the next step, the economic appraisal of the programme-for example, provision of bypass surgery serviceswhich is also necessary to rational long term planning, the economist may obtain reasonably good estimates of direct costs (principally NHS costs), but he is forced to make assumptions and value judgments in estimating indirect costs (mostly incurred by patients and their families) and in estimating benefits to both individual and to society. ${ }^{4}$ Various techniques have been proposed for putting figures on the value of human life for use in cost benefit studies of life saving programmes. The human capital approach, which probably has the longest history, assigns to an individual an economic value broadly represented by potential future earnings. ${ }^{5}$ To this may be added an implicit social value, approximately what society seems to have agreed to forego to prevent death per se. ${ }^{6}$ This approach works quite well and gives quite useful decision rules in middle life (and when there is negligible unemployment), but its extrapolation into the first and last decades of life causes problems

\footnotetext{
Department of Epidemiology and Community Medicine, University of Wales College of Medicine, Cardiff CF4 4XN

R R WEST, PHD, senior lecturer in community medicine
}

and yields quite doubtful decision rules. A further technique, nearly universally employed by health economists and made official by a Treasury rate, is to discount future benefits. Discounting future benefits, however, has yielded some decision rules that make no sense socially. ${ }^{7}$ This paper describes a new implied origin for the human capital approach and argues that the official Treasury discount rate should not be applied by planners of long run health care programmes.

\section{Human capital}

The classical human capital valuation, which estimates the value of an individual to society, takes first a man in middle age in employment with an annual income of, say, $£ 10000$ and adds future earnings, say, nine more years at the same salary, and a further five years in semiretirement at, say, $\$ 5000$ a year. All future earnings are normally discounted at $10 \%$ (see below) and this gives a present value of his future (of approximately $£ 72000$ ). To this narrowly defined economic value additions may be made for implicit social value of life per se. Various techniques have been suggested for

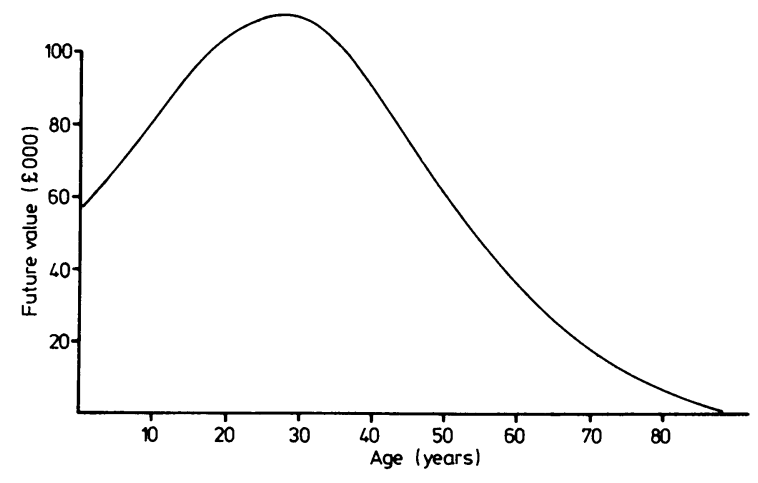

FIG 1-Human capital valuation as a function of age.

housewives; in effect, to give them salaries. Some debate surrounds whether women should be valued as men and whether or not allowances should be made for earning capacity according to social class or qualifications. The typical human capital valuation of potential future economic benefit has been extended into old age and extrapolated backwards into childhood, as shown in figure 1.8.10 Even the very elderly have a small probability of future earningthat is, some may still be self employed, general practitioners, or writers. The valuation of highly probable future earnings by children is reduced because of the discount rate. In attempts to evaluate screening programmes for neural tube defects or Down's syndrome the human capital model has been extrapolated backwards to birth and costs of caring for (and educating) the afflicted have been estimated and these have been used as measures of benefits when screening is offered. ${ }^{11}{ }^{12}$ Because many of the afflicted 
die in infancy and childhood and few reach middle life to become wage earners, the model seems superficially to provide a reasonable estimate of a negative value for the human capital of infants born with neural tube defects. Normal healthy infants, however, also require care and education for many years before becoming productive adults. Furthermore, the elderly require care (and medical treatment) and some middle aged adults require some elements of care. Since in human resource terms individuals contribute at certain times in their lives and consume at other times a new measure, the cumulative economic benefit, which sums credits to society and debits from society, seems to be a more appropriate measure of the average individual's value to society.

The cumulative economic benefit of an average individual as a function of age is shown diagrammatically in figure 2. At birth an infant has contributed little in the narrowly restricted economic sense to society. In the early years ( 0 -A in figure) a child costs society and a cumulative deficit or negative benefit results. After age $A$ the young adult contributes whether in paid employment or in unpaid employment (as a housewife) and society gains. Age B is where the negative childhood years are balanced by the positive early adult years. Age $C$ in late middle age marks the maximum contribution, after which time the elderly person becomes again a net cost to society. Death at age $\mathrm{D}$ signifies the end of the cumulative economic benefit to society of the individual. Whether $\mathrm{D}$ is above (or below) the axis indicates whether society makes an overall economic gain (or an overall economic loss). We would expect the average $\mathrm{D}$ to lie above the axis, which is analogous to the familiar concept of economic growth.

Individual variations clearly occur and the average illustrated above may be considered to be an integration of a family of many individual curves for all individuals making up society. Individual curves may differ quite markedly from the above in, for example, (i) a handicapped child (increased deficit: slope $0 \mathrm{~A}$ steeper and A more negative); (ii) a university education (prolonged deficit and therefore increased deficit, A and B at higher ages); (iii) low work capacity because of subnormality (reduced benefit, slopes $A B$ and BC less steep); (iv) early death (D early and higher); or (v) late death (D late and lower). The net economic gain to society may be quite high if death occurs suddenly and unexpectedly as early as 50 but could be negative if death occurs as late as 100 after years of dependency and a prolonged illness. Despite individual variations, usual individual cumulative economic benefit and the average cumulative economic benefit are as illustrated above, starting at birth at the origin, incurring loss in childhood, gain during adulthood, loss again in retirement, and ending fairly close to the axis.

\section{Discount rate}

Because of individual and societal preferences for the present over the future, benefits are normally discounted in estimates of their present value. This means that the equivalence of 100 certain units now of any article, commodity, or service-"good" in the economist's jargon-would be the promise of about 110 units next year. Discounting is widely used by economists and the practice is so well established that the Treasury advises an official rate-for example, $10 \%$ a year-although rates may vary with time and country. Discounting in cost benefit analysis of medical care programmes originates, like the traditional human capital theories, from programmes for otherwise fit middle aged men in employment, where a (present) medical intervention (a present cost) may confer future as well as present benefits. In cost benefit analysis of chronic disease, because treatment and care costs parallel economic and social benefits in time (now, next year, and the year after), discounting is largely unnecessary and the decision rules are relatively insensitive to choice of discount rate. ${ }^{6}$ Discounting is more appropriate in decision analysis of acute disease treatment programmes, when timing of costs and benefits do not concur because successful (present) intervention conveys benefit also in the future.

Discounting over long time spans and particularly backwards into childhood has produced highly misleading results. This can be illustrated by applying a discount rate of $10 \%$ a year to the data implied by figure 2 with the results presented diagrammatically in figure 3 . If a benefit 10 years hence is discounted by $10 \%$ each year for 10 years $\left((0.9)^{10}\right.$ gives approximately 0.35$)$ the present value of that benefit is judged to be reduced to $35 \%$. Similarly, a benefit 20 years hence $\left((0 \cdot 9)^{20}=0 \cdot 12\right)$ is reduced to about $12 \%$ and a benefit
30 years hence $\left.(0.9)^{30}=0.04\right)$ is reduced to about $4 \%$. After about 40 years contributions whether positive or negative have little influence on the discounted cumulative benefit. This is why the shape of figure 3 follows that of figure 2 only in the early years.

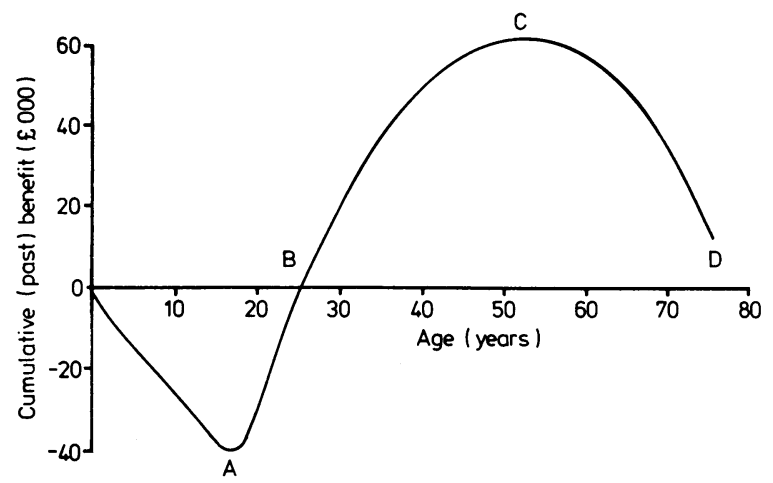

FIG 2-Cumulative economic benefit as a function of age

This was shown in a cost benefit analysis of screening for Down's syndrome. The paper concluded that the present value of future costs of caring for the afflicted, which could be partly averted by successful of screening and consequently could be put into the decision analysis as benefits, exceeded the direct costs of the screening programme. ${ }^{11}$ The paper also contained results, however, that showed that the present value cost of a $\vec{\omega}$ healthy newborn infant exceeded the present value cost of a newborn $\boldsymbol{\omega}$ Down's syndrome infant. The logical conclusion from the analysis was that 을 the economic gain to society from preventing any births far exceeded any $\vec{\bullet}$ economic gain to society resulting from the prevention of Down's syndrome births. ${ }^{7}$ No sophisticated screening techniques would be required to identify normal pregnancies so costs (per pregnancy) of terminating normal $\stackrel{\circ}{0}$ pregnancies would be substantially less than costs (per Down's syndrome pregnancy) of identifying and terminating some Down's syndrome pregnancies - an economic solution that is clearly quite unacceptable $\vec{\varphi}$ socially. Such nonsense conclusions should have warned us against these of calculations yet a more detailed cost benefit analysis of a neural tube defect screening programme some years later gave similar comparisons. ${ }^{12}$

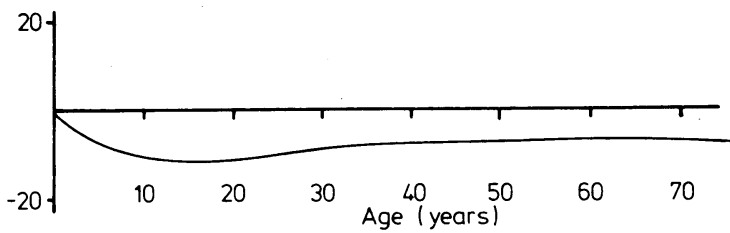

FIG 3-Discounted economic benefit as a function of age (figure 2 discounted at $10 \%$ a year)

The present value at birth of a healthy newborn baby may be negative $\frac{0}{2}$ because of commitment to care for the baby in the near future, but common $N$ sense tells us that the average cumulative value overall of an individual $D$ cannot be negative, as figure 3 would imply. Nor could the cumulative benefit of an individual be so uninfluenced by long term illness in adulthood or premature death as figure 3 would imply. The proposed cumulative economic benefit, shown diagrammatically in figure 2 , must be calculated at $\omega$ constant real terms prices. Although an individual may be born in, for $\sigma$ example, 1930, a net consumer till 1948, a net contributor from then until 1983 , and a net consumer again from then until death, society's account is balanced year by year by 55 million individuals (in Britain) at different $\mathscr{C}$ points on the age graph. Thus in any one year-for example, 1985-those who are contributing are keeping the then net consumers, as infants, $\bar{o}$ children, sick, infirm, and elderly. Furthermore, the balance is achieved in $\stackrel{\mathbb{D}}{\vec{P}}$

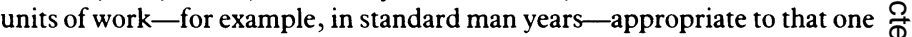
year-that is, in the economist's language at 1985 prices. Therefore, in $\varrho$ presenting diagrammatically the contribution over time of an average individual, it is logical to compare contributions and consumptions in constant $\odot$ units of work, or in constant real terms prices. Discounting with time is

continued on page 1141 


\section{Junior doctors' workload survey}

At its meeting on 1 October the Hospital Junior Staff Committee was encouraged to participate fully in the workload survey that the Office of Manpower Economics is conducting on behalf of the review body (12 October, p 1061). The outgoing chairman of the HJSC's negotiating subcommittee, Dr Timothy Fenton, has written to the mess presidents in the hospitals in those districts selected for the survey. Dr Fenton's letter is set out here.

"You will doubtless be aware that one of the major issues affecting hospital junior doctors at present time is that of hours of work. Progress is being made towards the reduction of unduly onerous rotas and the available statistical indicators suggest a steady decline in the overall hours of duty, of junior doctors, totalling some three hours per week, since 1981. Hours of work have clear implications for the remuneration of hospital junior staff and as such, are a legitimate interest for the review body on doctors' and dentists' remuneration, the independent body that recommends the levels of pay of doctors taking any part in the National Health Service.
"In its 15th report the review body indicated its intention to undertake a further study of juniors' hours of work, having previously conducted such a survey in 1981. This survey has been commissioned by the review body from its own secretariat, the Office of Manpower Economics and advice and assistance has been sought from the DHSS and from the profession. The Office of Manpower Economics has asked the Social Survey Division of the Office of Population Censuses and Surveys to carry out the sampling and interviewing on its behalf. As chairman of the negotiating subcommittee of the Hospital Junior Staff Committee, I have been asked to act as the liaison doctor for the survey and am writing to you to seek your cooperation in this exercise.

"The survey will be similar to that carried out in 1981 and will provide up to date information about the pattern of work and hours of duty of junior hospital doctors and dentists.

"Sixteen health districts in Great Britain are included in the survey and your district is among them. The districts have been selected to match as closely as possible those included in 1981. In the next few weeks an Office of Population Censuses and Surveys interviewer will visit district offices to produce a list of the junior doctors based at hospitals in the district. A representative sample of about half the doctors on full time NHS contracts will be selected. Interviewers will contact these doctors in November to ask them to take part in the survey. Each doctor will be asked a few basic questions-for example, grade, specialty-and then briefed on how to complete a simple diary questionnaire to record their hours of duty and the type of work carried out over a seven day period. The interviewer will see each doctor again at the end of the seven day period to collect the diaries and resolve any problems.

"Information collected about individual doctors will be held in strict confidence by the Office of Manpower Economics and the survey results reported only in aggregate so that individual doctors, hospitals, and districts are not identifiable.

"I should be very grateful if you could publicise this letter to all junior doctors in your hospital so that they know about the survey. The Office of Manpower Economics is also writing to consultant members of district management teams. If you, or they, have any immediate queries or foresee any difficulties please contact, in the first instance, the industrial relations officer for your region, or failing this, Mr J C Ford at BMA House (01 387 4499 ext 254), who will be dealing with day to day contact with the Office of Manpower Economics over detailed aspects of the survey."

\section{Correction}

\section{Life assurance reports}

In the report of increased fees for life assurance reports 5 October, $p$ 988) it was stated that an additional fee of $£ 11$ was payable in addition to the personal medicals attendant's report. This is incorrect; the additional fee is for agreement between the individual doctor and the office making the request.
Talking Point—continued from page 1140

invalid as it would make unfair comparisons of contributions and consumptions, which in the aggregate society are nearly balancing each other at any (real) point in time.

\section{Discussion}

The worth to society of an average individual at any point in his lifespan has been expressed in a modified human capital approach by the cumulative past economic benefit and the origin has been set at birth (age 0 ). Net consumption in childhood and in old age and net contribution during the productive years have been compared on equal terms without discounting, because at any point in time society comprises millions either consuming or contributing at real terms prices appropriate to that time. This economic model better describes implicit societal choice than previous human capital models, which have calculated future economic contributions alone or future economic consumptions and contributions at relatively high rates of discount. The difference has shown up particularly in the estimate of value of a newborn infant. Previous conventional human capital models have given various estimates of present value of an overall future cost in the region of $\$ 20000$ (even at 1979 prices). ${ }^{12}$ The present model would estimate an overall future contribution by the time that the infant has lived his full life of approximately $£ 10000$. Since this average credit accumulates over about 70 years, it fits with the concept of a small economic growth. The logical societal strategy implied by the estimates of the former model would be to abort all fetuses and avoid all childbirths, ${ }^{7}$ while the logical societal strategy implied by estimates of the latter model would be to replace the present population age distribution with a similar population age distribution in future years to maintain relatively constant the ratios of consuming children and elderly to contributing adults. The latter seems the more logical on simple common sense grounds.

The particular relevance to health service managers and planners of this model is in cost benefit analysis of screening programmes for neural tube defects or Down's syndrome. The principal narrowly defined economic costs of a screening programme depend on unit cost, prevalence of the disease, and sensitivity and specificity of the programme (not only of the test). Costs of neural tube defect screening programmes have been estimated at approximately $£ 5000$ per case terminated. ${ }^{12}$ The corresponding narrowly defined economic benefits of the screening programme are the costs of caring for the afflicted children that may be averted if screening is successful and if abortion is offered and accepted. Because many babies with neural tube defects die young and few survive to become adult contributors the cumulative overall cost per case may be in the region of $£ 25000$ (at 1979 prices). ${ }^{12}$ If averted by screening this represents the benefit per case of screening. This estimate of benefit is higher than previous estimates by discounters and therefore the difference between costs and benefits is greater than previously suggested by discounters. The conclusion must be that society can ill afford not to screen for neural tube defects.

\section{References}

1 Cochrane AL. Effectiveness and efficiency. London: Nuffield Provincial Hospitals Trust, 1972.

2 West RR. Effectiveness in medical care. In: West RR, Chown A. Achieving value for money in medical care. Cardiff: Welsh National School of Medicine, 1982.

3 Consensus development conference: coronary artery bypass grafting. Br Med f 1984;289:1527-9.

4 Mooney GH. Valuation of human life. London: Macmillan, 1977.

Petty W. Political arithmetic or a discourse concerning the extent and value of lands, people, buildings. London: Robert Church, 1699.

6 Buxton MJ, West RR. Cost benefit analysis of long term haemodialysis for chronic renal failure. $\mathrm{Br}$ Med f 1975;ii:376-9.

7 West RR. Screening for Down's syndrome. Br Med $\mathcal{f}$ 1976;i:1278-9.

8 Rice DP, Cooper BS. Economic value of human life. Am J Public Health 1967;57:1954-66.

9 Rice DP, Hodgson TA. Social and economic implications of cancer. World Health Stat $Q$ 1980:33:56-76.

10 Hartunian NS, Smart CN, Thompson MS. Incidence and economic costs of cancer, motor vehicle injuries, coronary heart disease and stroke: comparative analysis. Am $\mathcal{F}$ Public Health $1980 ; 70: 1249-60$.

11 Hagard $S$, Carter FA. Preventing the birth of infants with Down's syndrome: a cost benefit analysis. BrMed f 1976;i:753-6.

12 Henderson JB. Measuring benefits of screening for open neural tube defects. $\mathcal{J}$ Epidemiol Community Health 1982;36:214-9.

(Accepted 12 June 1985) 